\title{
Juxtaposition of the atrial appendages
}

INSERM

\section{Source}

INSERM. (1999). Orphanet: an online rare disease and orphan drug data base.

Luxtaposition of the atrial appendages. ORPHA:99100

Juxtaposition of the atrial appendages is a rare atrial appendage anomaly when both appendages are located on the left or the right side of the great arteries. It is asymptomatic and is usually diagnosed incidentally, but is frequently associated with other congenital heart diseases. 